\title{
GESTÃO PROCESSUAL E EFETIVIDADE JUDICIAL: UM ESTUDO DE CASO A PARTIR DO TRIBUNAL DO JÚRI COM MELHOR DESEMPENHO NO RANKING NACIONAL DO CNJ
}

\author{
PROCEDURAL MANAGEMENT AND JUDICIAL \\ EFFECTIVENESS: A CASE STUDY FROM THE JURY COURT \\ WITH THE BEST PERFORMANCE IN THE NATIONAL \\ RANKING OF THE NATIONAL COUNCIL OF JUSTICE
}

FABRÍCIO CASTAGNA LUNARDI Doutor e mestre em direito pela UnB. Professor permanente do PPGPD/Enfam. Juiz de direito do TJDFT. https://orcid.org/0000-0002-9512-8394

\begin{abstract}
RESUMO
O presente artigo tem o objetivo de investigar como a gestão processual pode impactar a efetividade de unidades judiciais, a fim de aumentar a celeridade do processo e a qualidade da prestação jurisdicional, bem como estabelecer métricas para medição do desempenho. Para atingir os seus escopos, a investigação se desenvolve a partir de uma linha crítico-metodológica e jurídico-comparativa, buscando analisar a gestão processual na perspectiva de direito comparado. Para aferir o impacto da gestão processual no Judiciário, será utilizada a metodologia estudo de caso, analisando-se o contexto da unidade judicial que ficou em primeiro lugar no ranking nacional de desempenho, medido pelo Conselho Nacional de Justiça. Ao final, conclui-se que a gestão processual produz grandes impactos no desempenho judicial, com aumento da produtividade, redução da taxa de congestionamento, diminuição do acervo processual, além de melhorar a qualidade dos julgamentos, razão pela qual se propõe que as unidades judiciais criem e implementem um modelo estratégico de gerenciamento de processos, que respeite as garantias das partes e contribua para um Judiciário mais efetivo.
\end{abstract}

Palavras-chave: gestão processual; efetividade; desempenho; judiciário; Tribunal do Júri de Samambaia. 


\section{ABSTRACT}

This article aims to investigate how procedural management can impact the effectiveness of judicial units, in order to increase the speed of the process and the quality of jurisdictional provision, as well as establish metrics for measuring performance. To achieve its scope, the investigation is developed from a critical-methodological and legal-comparative line, seeking to analyze the procedural management from the perspective of comparative law. To assess the impact of procedural management on the Judiciary, the case study methodology will be used, analyzing the context of the judicial unit that ranked 1st in the national ranking of performance, measured by the National Council of Justice. In the end, it is concluded that the procedural management produces great impacts on judicial performance, with increased productivity, reduction of the congestion rate, reduction of the number of processes, in addition to improving the quality of judgments, which is why it is proposed that the judicial units create and implement a strategic process management model that respects the guarantees of the parties and contributes to a more effective judiciary.

Keywords: procedural management; effectiveness; performance; judiciary; Criminal Jury of Samambaia.

Recebido: 2-6-2021

Aprovado: 28-6-2021

\section{SUMÁRIO}

1 Introdução. 2 Os dados da (in)efetividade da Justiça brasileira: qual é o problema? 3 Como melhorar o desempenho judicial? Perspectivas a partir da gestão de processos em direito comparado. 4 Estudo do caso de uma unidade judicial com alto desempenho: o Tribunal do Júri de Samambaia. 4.1 O desempenho do Tribunal do Júri de Samambaia. 4.2 Diagnóstico dos problemas enfrentados pelo Tribunal do Júri de Samambaia no ano de 2017. 4.3 Medidas para reduzir o quantitativo de audiências de instrução, aumentando a celeridade do processo e a qualidade da prova. 5 Conclusão. Referências. 


\section{INTRODUÇÃO}

Embora tenha havido uma série de reformas processuais no Brasil nos últimos anos, com o objetivo declarado de dar maior celeridade e efetividade ao sistema de justiça brasileiro, elas não têm se revelado suficientes para tal propósito, diante da manutenção de uma burocracia processual (LUNARDI, 2019). De outro lado, as medidas de gestão têm sido apontadas como grandes aliadas do Poder Judiciário para melhoria do seu desempenho. (CONSELHO NACIONAL DE JUSTIÇA, 2020a, p. 93)

Desse modo, é imprescindível investigar qual é o impacto da gestão processual nas unidades judiciais, quais são as medidas que poderiam ser adotadas para melhorar o seu desempenho, bem como quais as métricas que podem ser utilizadas para medi-lo.

A partir dessas premissas, este artigo tem o objetivo de investigar como a gestão processual pode impactar o desempenho de unidades judiciais, a fim de aumentar a celeridade do processo e a qualidade da prestação jurisdicional. Além disso, também busca traçar métricas para medição do desempenho judicial, analisando-o do ponto de vista da produtividade e da qualidade.

Para atingir os seus escopos, essa investigação se desenvolve a partir de uma linha crítico-metodológica, com base na análise de dados, bem como jurídico-comparativa, buscando analisar a gestão processual na perspectiva de direito comparado. Para aferir o impacto da gestão processual no Judiciário, será empregada a metodologia estudo de caso, utilizando-se o contexto de uma unidade judicial.

Assim, para identificar os pontos de (in)efetividade da Justiça brasileira e, em especial, nos tribunais do júri, serão analisados diversos dados de produtividade. Em seguida, buscar-se-á definir a concepção de gestão processual e investigar, sob uma perspectiva de direito comparado, como vem sendo tratada no plano normativo em países como Portugal e Reino Unido. Para testar e investigar o seu impacto no Judiciário, serão examinados a gestão processual e o comportamento dos diversos atores em uma unidade judicial de alto desempenho, sendo eleito para tal finalidade o Tribunal do Júri de Samambaia, por ter obtido o primeiro lugar no ranking nacional nos anos-base 2019 e 2020. Nesse tocante, afere-se, inicialmente, o desempenho dessa unidade judicial, para, logo depois, analisar qual foi o diagnóstico dos problemas e as medidas de 
gestão processual utilizadas para melhorar o seu desempenho, a fim de se aferir os impactos gerados e se podem ser exportados para outras unidades judiciais congêneres.

\section{OS DADOS DA (IN)EFETIVIDADE DA JUSTIÇA BRASILEIRA: QUAL É O PROBLEMA?}

A Pesquisa Justiça em Números 2018 mostrou que, durante toda a série histórica, 2017 marca a redução do estoque de processos. Com efeito, "durante o ano de 2017, ingressaram 29,1 milhões de processos e foram baixados 31 milhões (CONSELHO NACIONAL DE JUSTIÇA, 2018, p. 73), ou seja, a redução do estoque não ocorreu em razão da diminuição da litigiosidade ou do ingresso de demandas no Judiciário, senão do aumento da produtividade?.

Nos anos seguintes, 2018 e 2019, também houve aumento da produtividade. De acordo com o Relatório Justiça em Números 2020, "durante o ano de 2019, em todo o Poder Judiciário, ingressaram 30,2 milhões de processos e foram baixados 35,4 milhões" (CONSELHO NACIONAL DE JUSTIÇA, 2020a, p. 93). Novamente, foi o aumento da produtividade que garantiu a redução do acervo do Judiciário, visto que "houve crescimento dos casos novos em 6,8\%, com aumento dos casos solucionados em 11,6\%". (CONSELHO NACIONAL DE JUSTICCA, 2020a, p. 93)

- Conselho Nacional de Justiça atribui essa melhoria de desempenho a políticas de gestão judicial, bem como a ferramentas de gestão, controle e incentivo ao aprimoramento da prestação jurisdicional². No entanto, na Justiça brasileira, o tempo do processo continua elevado ${ }^{3}$, o que demanda a adoção de medidas para melhorar o desempenho judicial.

\footnotetext{
"Em 2017, foi o primeiro ano em que o volume de baixados superou o patamar de 30 milhões de casos solucionados." (CONSELHO NACIONAL DE JUSTIÇA, 2018, p. 73)

2 "Os resultados positivos mostram reflexo das políticas que vêm sendo adotadas pelo CNJ, como Metas Nacionais e Prêmio CNJ de Qualidade, como ferramentas de gestão, de controle e incentivo ao aprimoramento da prestação jurisdicional. Em 2019, o acervo retornou ao patamar do ano de 2015, quando, na época, a tendência era unicamente pelo crescimento." (CONSELHO NACIONAL DE JUSTIÇA, 2020a, p. 93)

3 "Os tribunais superiores e as Justiças Eleitoral e Militar Estadual se destacam por apresentar tempo médio do acervo inferior a dois anos. O tempo médio do acervo da Justiça do Trabalho aumentou no último ano e pela primeira vez na série histórica foi superior a três anos. Já as Justiças estadual e Federal apresentam acervo de, em média, cinco anos e quatro meses." (CONSELHO NACIONAL DE JUSTIÇA, 2O2Oa, p. 181).
} 
Nesse ínterim, os tribunais do júri brasileiros também têm sido objeto de grande preocupação nos últimos anos, do ponto de vista da efetividade, tendo em vista que tratam de crimes que atingem o bem jurídico mais valioso na sociedade: a vida, e, de outro lado, padecem de grande demora na resposta dada pelo Judiciário.

De acordo com o Diagnóstico das Ações Penais de Competência do Tribunal do Júri, em 2018, de todas decisões que puseram fim ao processo, 32,4\% extinguiram a punibilidade do acusado (CONSELHO NACIONAL DE JUSTICCA, 2019, p. 18). Isso significa que, em quase um terço dos processos do júri, não houve julgamento pela absolvição ou condenação do réu. A mesma pesquisa mostrou que "foram realizadas mais de uma sessão de julgamento em 59\% dos casos" (CONSELHO NACIONAL DE JUSTIÇA, 2019, p. 18). Além disso, a pesquisa também constatou que $52 \%$ dos processos duraram quatro anos ou mais, dos quais 26\% chegaram a tramitar por mais de oito anos (CONSELHO NACIONAL DE JUSTICCA, 2019, p. 18). Além disso, a taxa de congestionamento média entre os tribunais do júri, no ano-base 2020, foi de 86,4\%. (CONSELHO NACIONAL DE JUSTICCA, 2O2Ob)

De outro lado, alguns tribunais do júri têm se destacado positivamente pelo seu desempenho, como o Tribunal do Júri de Samambaia, que ficou em primeiro lugar no ranking nacional de desempenho nos anos-base 2019 e 2020. Esta unidade judicial teve a menor taxa de congestionamento nos referidos anos, atingindo 29,5\% e 31,9\% em 2019 (CONSELHO NACIONAL DE JUSTIÇA, 2020d) e 2020 (DISTRITO FEDERAL, 2021b; MONTENEGRO, 2021), respectivamente. Assim, tomando-se como base o ano de 2020, teve uma taxa de congestionamento que é quase um terço da média nacional.

Isso mostra que, a par da melhoria de alguns indicadores do Judiciário, ainda há um grande problema de inefetividade judicial, bem como um grande potencial para que as medidas de gestão sejam exploradas e implementadas em unidades judiciais, a fim de que se melhore o seu desempenho.

Dessa forma, é importante, inicialmente, conhecer qual é o panorama legislativo, internamente e fora do país, que pode contribuir para a criação de um modelo de gestão processual que seja tendente a melhorar o desempenho judicial. 


\section{COMO MELHORAR O DESEMPENHO JUDICIAL? PERSPECTIVAS A PARTIR DA GESTÃO DE PROCESSOS EM DIREITO COMPARADO}

A expressão "gestão de processos" é uma forma específica de gestão, a qual busca entender os processos que são geridos pela organização (ARAúJO; GARCIA; MARTINES, 2019, p. 26). Tal metodologia de gestão é utilizada tanto pelo setor público quanto pelo setor privado, de modo que gestão de processos não significa necessariamente processos judiciais, embora estes possam ser incluídos nessa forma de gestão. A gestão de processos não se confunde com a gestão por processos. Esta expressão designa uma abordagem administrativa, enquanto aquela, um estilo de organização e gerenciamento (SORDI, 2018, p. 36-37) em que a organização passa a ser orientada por seus processos. (ARAÚJO; GARCIA; MARTINES, 2019, p. 26)

No Brasil, as legislações processuais não fazem referência à gestão de processos ${ }^{4}$. No entanto, em alguns outros países, ela é um dever processual imposto ao juiz pela legislação, como ocorre em Portugal e no Reino Unido.

O Código de Processo Civil Português (Lei n. 41/2013) estabelece expressamente, no seu artigo 6으, o "dever de gestão processual". Nesse sentido, dispõe que "cumpre ao juiz [...] dirigir ativamente o processo e providenciar pelo seu andamento célere, promovendo oficiosamente as diligências necessárias ao normal prosseguimento da ação", bem como indeferir "o que for impertinente ou meramente dilatório", adotar "mecanismos de simplificação e agilização processual que garantam a justa composição do litígio em prazo razoável" (PORTUGAL, 2013). Além disso, o princípio da gestão processual incrementa uma atuação responsiva não somente do magistrado, mas também de todas as partes e de todos os atores que atuam no processo. (SILVA, 2011, p. 146)

De outro lado, o Código de Processo Penal de Portugal (Decreto-Lei n. 1.978/1987), embora não estabeleça expressamente o "dever de gestão processual", prevê diversas medidas para evitar protelações e atrasos,

\footnotetext{
${ }^{4}$ Além disso, a própria noção de governança judicial é pouco explorada no âmbito das unidades judiciais, sendo escassos os estudos teórico-empíricos que tenham como objeto órgãos do Poder Judiciário, como apontam Luiz Akutsu e Tomás de Aquino Guimarães (2012).
} 
tais como a "sanção pela prática extemporânea de actos processuais" (artigo 107), a "aceleração de processo atrasado" (artigo 108) e a "tramitação do pedido de aceleração" (artigo 109). Esta última medida, proposta contra o magistrado, estabelece que a decisão a ser tomada pode consistir em "propor ou determinar as medidas disciplinares, de gestão, de organização ou de racionalização de métodos que a situação justificar" (artigo 109, item 5, letra d). (PORTUGAL, 1987)

No Reino Unido, os problemas da burocracia dos processos judiciais foram objeto de ampla reforma (a conhecida Woolf's Reform), que culminou no Civil Procedure Rules (CPR) de 1998, primeira codificação processual civil deste país, atualmente vigente. Os problemas enfrentados pela Woolf's Reform diziam respeito sobretudo ao papel passivo desempenhado pelos juízes, que apenas reagiam às provocações das partes e seus advogados; à utilização abusiva de recursos nos tribunais; à falta de cumprimento de ordens judiciais e à deficiência de instrumentos para coibi-la; à desilusão entre os jurisdicionados; à "duração demasiada da solução de litígios satélites sobre questões processuais"; e ao "crescimento dos custos na utilização da jurisdição (ALMEIDA, 2011, p. 289). Diante desses problemas, "juízes, advogados e acadêmicos pactuavam o mesmo sentimento de que a gestão do processo deveria mudar de mãos". (ALMEIDA, 2011, p. 291)

Nesse sentido, o Civil Procedure Rules de 1998 traz, expressamente, no item 1.4 da Parte 1, o dever de gestão dos conflitos ou gerenciamento de casos (Court's duty to manage cases) como objetivo preponderante (overriding objective) ${ }^{5}$. Para cumprir esse dever, há uma série de orientações ao magistrado ${ }^{6}$, bem como lhe são conferidos, no item 3.1

\footnotetext{
5 "PART 1 - OVERRIDING OBJECTIVE [...] - Court's duty to manage cases - 1.4 (1) The court must further the overriding objective by actively managing cases." (REINO UNIDO, 1998)

6 "Court's duty to manage cases - 1.4 [...] (2) Active case management includes: (a) encouraging the parties to co-operate with each other in the conduct of the proceedings; (b) identifying the issues at an early stage; (c) deciding promptly which issues need full investigation and trial and accordingly disposing summarily of the others; (d) deciding the order in which issues are to be resolved; (e) encouraging the parties to use an alternative dispute resolution procedure if the court considers that appropriate and facilitating the use of such procedure; ( $f$ ) helping the parties to settle the whole or part of the case; (g) fixing timetables or otherwise controlling the progress of the case; $(h)$ considering whether the likely benefits of taking a particular step justify the cost of taking it; (i) dealing with as many aspects of the case as it can on the same occasion; ( $j$ ) dealing with the case without the parties needing to attend at court; ( $k$ ) making use of technology; and (I) giving directions to ensure that the trial of a case proceeds quickly and efficiently." (REINO UNIDO, 1998)
} 
da Parte 3, diversos poderes de gestão (The court's general powers of management). (REINO UNIDO, 1998)

No âmbito processual penal, o Criminal Procedure Rules de 2020 estabelece, para o âmbito processual penal, o dever do tribunal de gerir ativamente os processos (item 3.2) ${ }^{7}$. Essa gestão judicial ativa inclui, no processo penal: a) a identificação dos problemas reais logo no início do processo; b) a identificação, no início do processo, da necessidade de oitiva de cada testemunha; c) garantir às partes segurança e previsibilidade acerca do que será realizado no processo, por quem e quando, sobretudo pelo estabelecimento antecipado de um calendário para o tramitar do processo; d) monitorar o tramitar do processo e o cumprimento das suas instruções; e) assegurar que as provas, impugnadas ou não, sejam apresentadas da forma mais rápida e clara; f) desencorajar atrasos no processo, resolvendo o maior quantitativo possível de aspectos do processo na mesma ocasião, e evitando audiências desnecessárias; g) encorajar as partes a cooperar na evolução do caso; e h) fazer uso de tecnologia8. Além disso, ao gerenciarem ativamente os processos, os juízes devem dar, o mais cedo possível, todas as orientações adequadas às necessidades do caso $^{9}$. O subitem 4 do item 1.4 do Criminal Procedure Rules de 2020 prevê a utilização de sistemas de videoconferência para a realização de audiências criminais. Além disso, o subitem 5 do item 1.4 do mesmo código também prevê o uso de recursos telefônicos para algumas hipóteses de audiência. (REINO UNIDO, 2020)

Os códigos processuais de Portugal e do Reino Unido fornecem bons exemplos de medidas que podem e devem ser adotadas pela legislação processual brasileira no sentido de diminuir a burocracia processual e implementar ferramentas jurídicas de gestão, buscando trazer mais efetividade à Justiça brasileira.

\footnotetext{
7 "The duty of the court - 3.2. - (1) The court must further the overriding objective by actively managing the case." (REINO UNIDO, 2O2O)

8 "(2) Active case management includes - (a) the early identification of the real issues; (b) the early identification of the needs of witnesses; (c) achieving certainty as to what must be done, by whom, and when, in particular by the early setting of a timetable for the progress of the case; (d) monitoring the progress of the case and compliance with directions; (e) ensuring that evidence, whether disputed or not, is presented in the shortest and clearest way; ( $f$ ) discouraging delay, dealing with as many aspects of the case as possible on the same occasion, and avoiding unnecessary hearings; ( $\mathrm{g}$ ) encouraging the participants to co-operate in the progression of the case; and ( $h$ ) making use of technology." (REINO UNIDO, 2020)

9 "(3) The court must actively manage the case by giving any direction appropriate to the needs of that case as early as possible." (REINO UNIDO, 2020)
} 
De outro lado, é possível observar que há diversas medidas jurídicas disponíveis no sistema jurídico brasileiro para, dentro das regras e com base em metodologias de gestão, conceber um modelo estratégico de gerenciamento de processos, que respeite as garantias das partes, esteja alicerçado na confiança e na cooperação, confira mais celeridade e qualidade ao processo, para que se alcance um processo mais efetivo. Desse modo, a questão central é como reunir as ferramentas jurídicas existentes e as medidas de gestão para atingir esse propósito.

Para responder a essa questão, busca-se a seguir, a partir do estudo do caso de uma unidade judicial com alto desempenho, encontrar respostas para medidas de gestão capazes de conferir mais celeridade ao processo, mas, ao mesmo tempo, testar se essas medidas também respeitam as garantias das partes, bem como se conferem maior qualidade aos atos processuais.

\section{ESTUDO DO CASO DE UMA UNIDADE JUDICIAL COM ALTO DESEMPENHO: O TRIBUNAL DO JÚRI DE SAMAMBAIA}

A fim de investigar o impacto da gestão de processos no desempenho do Judiciário, é necessário analisar como ela ocorre no contexto de uma unidade judicial. Desse modo, para testar tais conceitos e ferramentas ao Judiciário, será utilizada a metodologia estudo de caso, para, com base em dados empíricos, explicar, explorar e descrever o fenômeno da gestão processual em uma unidade judicial. A escolha dessa metodologia se deve ao fato de que, como aponta Kathleen Eisenhardt (1989, p. 548-549), o estudo de caso permite a testabilidade e a verificação de validade empírica, que surgem da ligação íntima com a evidência empírica, além de ser adequada para novas áreas de pesquisa e para testar elementos de teorias (YIN, 2009), o que se propõe nesta pesquisa. Além disso, é um método válido em pesquisas tanto no direito como na administração, o que é imprescindível neste caso, visto que ambas as áreas do conhecimento estão correlacionadas nesta pesquisa, conferindo-se validade interna e externa à investigação científica, como ressalta Lisa Ellram (1996). Para analisar o impacto da gestão processual nas unidades judiciais, foi escolhida a Vara do Tribunal do Júri de Samambaia, porque ela ficou em primeiro lugar no ranking nacional de desempenho dos anos de 2020 e 2021, que tiveram como base a produtividade nos anos de 2019 e 2020, respectivamente. Assim, com fundamento na metodologia estudo de caso, busca-se analisar a gestão 
processual inserida em um contexto no qual ela é aplicada, permitindo-se extrair quais os seus reais impactos para a efetividade judicial, entendida como a celeridade do processo e a qualidade das decisões.

\subsection{O desempenho do Tribunal do Júri de Samambaia}

Antes de analisar a gestão processual e as medidas adotadas pelo Tribunal do Júri de Samambaia, é importante analisar o seu contexto, a quantidade de processos distribuídos e os resultados obtidos pela gestão processual, bem como apontar a existência de outros fatores que podem impactar no seu desempenho.

O Tribunal do Júri de Samambaia é a unidade judiciária com a terceira maior distribuição entre tribunais do júri da Justiça do Distrito Federal, conforme se observa do gráfico a seguir. (DISTRITO FEDERAL, 2021a, p. 3)

\section{TRIBUNAIS DO JÚRI}

Total de Processos Distribuidos (2017 - 2020)

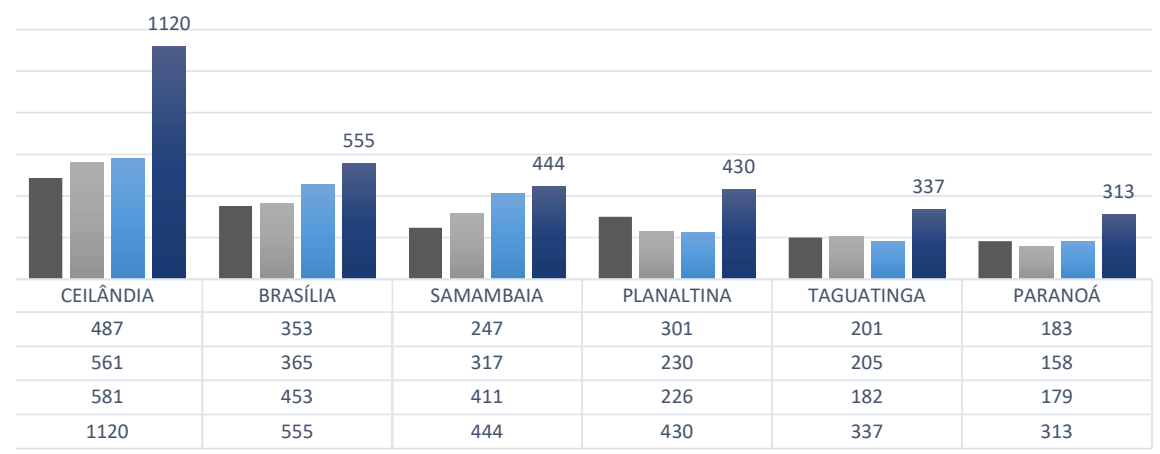

No final do mês de agosto de 2017, a unidade judicial contava com um acervo de 823 processos (DISTRITO FEDERAL, 2017). No final do mês de dezembro de 2020, a vara estava com o total de 241 processos (DISTRITO FEDERAL, 2020). Em outras palavras, houve uma redução de $70,7 \%$ do acervo.

Com isso, o Tribunal do Júri de Samambaia que, no final de 2017, tinha o terceiro maior acervo entre as unidades exclusivas de Tribunal do Júri da Justiça do Distrito Federal, passou a ter, no final do mês de novembro de 2020 (este foi o período que constou na pesquisa realizada 
no PA SEI 0021803/2020, o menor acervo entre tais unidades judiciais, como se observa do gráfico a seguir. (DISTRITO FEDERAL, 2021a)

\section{TRIBUNAIS DO JÚRI}

Total de Processos Distribuidos (2017 - 2020)

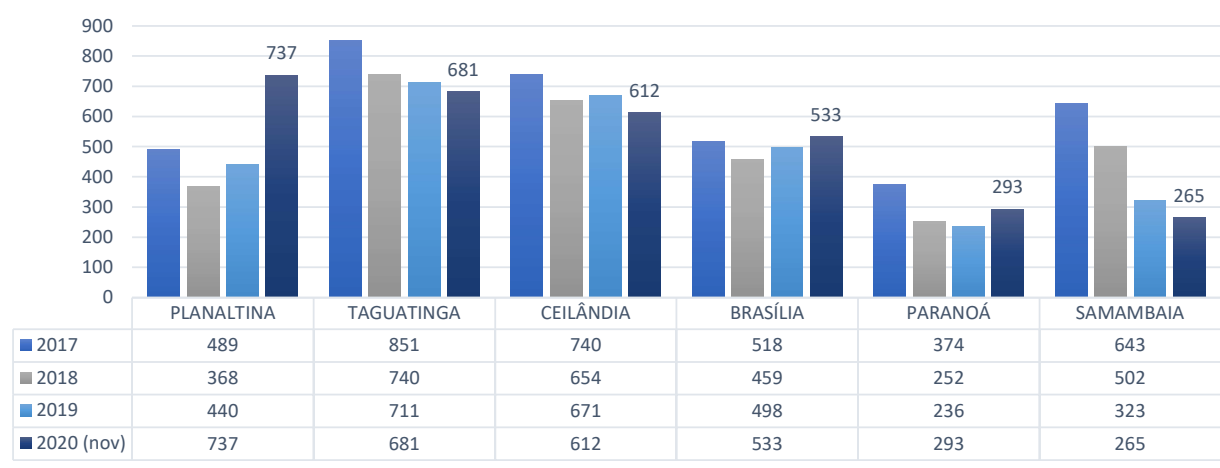

O Tribunal do Júri de Samambaia ficou em primeiro lugar no ranking nacional de desempenho por dois anos consecutivos, 2019 e 2020, segundo dados divulgados em 2020 e 2021, respectivamente, pelo Departamento de Pesquisas Judiciárias do Conselho Nacional de Justiça (DPJ/CNJ), conforme tabelas a seguir:

Ano 2021/Ano-base 2020 (DISTRITO FEDERAL, 2021b):

\section{Melhores desempenhos (menores taxas de congestionamento):}

\begin{tabular}{|c|l|c|c|c|c|}
\hline \multicolumn{1}{|c|}{$\begin{array}{c}\text { Unidade } \\
\text { Judiciária }\end{array}$} & Município sede & Tribunal & $\begin{array}{c}\text { Taxa de } \\
\text { Congestionamento } \\
\text { Líquida }\end{array}$ & $\begin{array}{c}\text { Taxa de } \\
\text { Congestiona- } \\
\text { mento }\end{array}$ \\
\hline $\begin{array}{l}\text { TRIBUNAL JÚRI DE } \\
\text { SAMAMBAIA }\end{array}$ & SAMAMBAIA & TJDFT & $30,5 \%$ & $31,9 \%$ \\
\hline $\begin{array}{l}\text { SO JÚRI DE } \\
\text { BRASÍLIA }\end{array}$ & BRASÍLIA & TJDFT & $39,5 \%$ & $43,3 \%$ \\
\hline $\mathbf{3 0}$ & $\begin{array}{l}\text { 2a VARA } \\
\text { DO JÚRI DA } \\
\text { COMARCA DE } \\
\text { FORTALEZA }\end{array}$ & FORTALEZA & TJDFT & $45,3 \%$ & $49,4 \%$ \\
\hline
\end{tabular}


*Dados do DPJ/CNJ

Ano 2020/Ano-base 2021 (CONSELHO NACIONAL DE JUSTIÇA, 2020d):

Melhores desempenhos (menores taxas de congestionamento):

\begin{tabular}{|c|c|c|c|c|}
\hline & Unidade Judiciária & Município & Estoque & $\begin{array}{c}\text { Taxa de } \\
\text { Congestionamento }\end{array}$ \\
\hline 10 & $\begin{array}{l}\text { TRIBUNAL DO JÚRI DE } \\
\text { SAMAMBAIA }\end{array}$ & SAMAMBAIA & 110 & $29,5 \%$ \\
\hline 2 o & $\begin{array}{l}\text { TRIBUNAL DO JÚRI DE } \\
\text { CEILÂNDIA }\end{array}$ & CEILÂNDIA & 279 & $44,6 \%$ \\
\hline 3은 & $\begin{array}{l}\text { CUIABÁ - PRIMEIRA } \\
\text { VARA CRIMINAL }\end{array}$ & CUIABÁ & 80 & $45,7 \%$ \\
\hline
\end{tabular}

A prática de "Gestão processual estratégica no Tribunal do Júri", desenvolvida na referida unidade judicial, foi inscrita no Banco de Boas Práticas do CNJ, na categoria gestão processual (LUNARDI, 2020a), e foi uma das cinco finalistas do 17으êmio Innovare, de 2020 (CONSELHO NACIONAL DE JUSTIÇA, 2020c), também sendo inscrita no Banco de Boas Práticas do Instituto Innovare. Além disso, foi objeto do livro de gestão do CNJ, intitulado Gestão Processual no Tribunal do Júri. (LUNARDI, 2020b)

Desse modo, é imprescindível investigar quais as medidas e metodologias de gestão processual adotadas na unidade judicial que levaram ao seu elevado desempenho, bem como avaliar se o aumento de produtividade ocorreu com ou sem melhoria na qualidade da prestação jurisdicional. 


\subsection{Diagnóstico dos problemas enfrentados pelo Tribunal do Júri de Samambaia no ano de 2017}

Para atingir o objetivo de analisar quais os principais problemas e desafios que foram primordialmente enfrentados pela unidade judicial, será utilizado o Princípio de Pareto ${ }^{10}$. A partir dessa identificação, serão analisadas as principais medidas de gestão judicial e, mais especificamente, de gestão processual adotadas no Tribunal do Júri de Samambaia que geraram maior impacto no desempenho da vara. Para tanto, será realizada pesquisa quantitativa, realizando-se cruzamentos de dados para analisar o momento em que as medidas foram adotadas e como elas impactaram o seu desempenho, em termos de produtividade. Nesse tocante, também será utilizada a Teoria dos Jogos, a fim de investigar como os atores se comportam diante das medidas de gestão adotadas.

Para esta pesquisa, foi analisado o interregno de 2017 até o final de 2020, ou seja, o período que compreende o ano em que o magistrado atual assumiu a unidade com a sua equipe até o ano-base em que ela conquistou o primeiro lugar no ranking nacional de desempenho pelo segundo ano consecutivo.

A fim de constatar quais foram as principais modificações em termos de gestão, é necessário aferir, inicialmente, qual o diagnóstico realizado em 2017.

De acordo com a análise documental e a prática inscrita no Banco de Boas Práticas do Conselho Nacional de Justiça (LUNARDI, 2020a), em 2017, foi possível constatar que a unidade judicial passava pelos seguintes problemas: a) muitas audiências de instrução por processo (ainda que o CPP preveja, como regra, a audiência una de instrução e julgamento), havendo processos com até nove audiências; b) pauta muito longa para marcação de audiências de instrução, que chegava a dez meses, gerando excesso de prazo (e, consequentemente, habeas corpus para soltura de réus presos por excesso de prazo da prisão cautelar); c) poucos espaços na pauta para sessões plenárias de júri; d) pautas de sessões plenárias de júri muito extensas (chegando a dez meses); e) congestionamento de processos nas fases de marcação de audiência de instrução e de designação da sessão plenária do júri; f) demora de vários anos para o

\footnotetext{
$\overline{10} \mathrm{O}$ Princípio de Pareto permite facilitar a identificação e visualização dos principais problemas, possibilitando a concentração de esforços sobre eles.
} 
julgamento de processos, com riscos de ocorrência de prescrição penal; e g) sessões de júri desnecessariamente longas. (LUNARDI, 2020a)

A partir desses problemas, na unidade judicial, houve a realização de diagnóstico e o mapeamento do processo, de modo a: a) identificar os principais entraves e gargalos que geravam inefetividade processual; b) verificar os motivos que levavam ao grande número de audiências de instrução e ao adiamento de sessões plenárias de júri; c) propor, a partir da prática, soluções viáveis para evitar o adiamento de audiências de instrução e de sessões plenárias de júri; d) criar medidas inovadoras para otimizar os atos processuais, minimizar as possibilidades de nulidades, respeitar todas as garantias processuais das partes, aumentar a qualidade e a celeridade dos atos processuais. (LUNARDI, 2020a)

\subsection{Medidas para reduzir o quantitativo de audiências de instrução, aumentando a celeridade do processo e a qualidade da prova}

A fim de investigar quais as medidas utilizadas para melhorar a gestão processual no Júri de Samambaia, ter-se-á como base a prática inscrita no Banco de Boas Práticas do CNJ (LUNARDI, 2020a). Segundo consta nesse banco, a prática foi desenvolvida e implementada a partir da realização de diagnósticos, da criação de medidas viáveis e do acompanhamento de resultados, descritos resumidamente a seguir.

Diagnóstico 1: na maioria dos processos, o Ministério Público e a defesa requeriam a intimação das vítimas/testemunhas no endereço constante no inquérito. Ocorre que, quando se trata de fato criminoso e inquérito antigo, é comum que elas tenham mudado de endereço (em razão do grande lapso temporal decorrido entre a data da denúncia e o momento em que compareceram à delegacia e informaram o seu endereço). Medida adotada: criou-se a rotina de, em denúncias por fatos antigos, determinar a intimação do Ministério Público para que diligencie o endereço atualizado da testemunha, antes da primeira audiência (se o endereço não estivesse atualizado). Resultado observado: redução significativa de adiamentos de audiências de instrução em inquéritos antigos.

Diagnóstico 2: muitas audiências de instrução realizadas para um único processo, em razão de redesignações para oitiva de vítima/ testemunha cuja intimação resultou infrutífera. Medida adotada: criação de um cronograma de intimações, para realização de diversas tentativas de intimação das vítimas/testemunhas antes da audiência, da seguinte 
forma: a) 55 dias antes da audiência, expede-se o mandado de intimação; b) 20 dias depois da expedição, cobra-se do oficial de justiça o seu cumprimento; c) se o mandado de intimação for infrutífero, dá-se vista ao Ministério Público e/ou à defesa para indicação, no prazo de 48 horas, de novo endereço da pessoa a ser ouvida; d) nova expedição de mandado de intimação; e e) repete-se esse ciclo reiteradamente até a data da audiência. Resultado observado: redução drástica do quantitativo de adiamentos de audiências, seja pela efetiva intimação das vítimas e/ou testemunhas para o ato, ou porque as partes desistem da sua oitiva, visto que, após várias tentativas, não foi possível a sua localização.

Diagnóstico 3: muitos adiamentos de audiências de instrução por pedidos de vista do Ministério Público ou da defesa para analisar melhor o processo, quando ausente determinada vítima e/ou testemunha. Medida adotada: criação de pauta de audiências especificada, com indicação dos seguintes elementos: a) nome das partes, com a folha dos autos ou o ID (número identificador, em processo eletrônico) em que foi certificada a sua intimação; b) nomes do réu e da vítima, com indicação de folha ou ID onde consta que foram intimados; c) o nome das pessoas a serem ouvidas, com indicação do grau de parentesco entre elas e a vítima e/ou o réu; d) se a pessoa a ser ouvida foi devidamente intimada e, em caso negativo, a especificação sobre se a parte foi intimada para fornecer novo endereço; e) folha ou ID em que consta a folha de antecedentes penais do réu. Resultado observado: a elaboração da pauta especificada, além de permitir sanear várias irregularidades processuais antes da audiência, pela necessidade de análise processual para elaborá-la, ainda permite que as partes, no ato da audiência, possam ter acesso fácil às informações do processo, para apreciar mais rapidamente a situação (sem precisar pedir prazo para vista dos autos) e para que o juiz possa decidir de plano ou fazer alguma proposição para o bom andamento do processo. Com isso, houve uma redução drástica de pedidos de vista e de conclusão dos autos para decisão, com grande redução do quantitativo de adiamentos de audiência de instrução.

Diagnóstico 4: adiamentos de audiências por não comparecimento de vítimas/testemunhas não localizadas ou que se esqueceram da data da audiência. Medida adotada: tentativa de realização de contato telefônico solicitando o seu comparecimento (sem caráter de intimação formal), no próprio ato da audiência, a partir do número de celular que consta no processo, ou pelo número fornecido pela vítima ou testemunhas que comparecem à audiência, quando possuem essa informação. Resultado observado: comparecimento da testemunha de forma imediata ou, após 
suspensão da audiência, no mesmo dia, evitando-se o adiamento da audiência.

Diagnóstico 5: não comparecimento de testemunhas intimadas. Medida adotada: condução coercitiva para a audiência, na mesma data, suspendendo-se o ato enquanto se aguarda o resultado da condução e dando-se seguimento às demais audiências. Resultado observado: redução do quantitativo de adiamentos de audiências.

Diagnóstico 6: demora desnecessária: a) na apresentação de alegações finais pelas partes, cujo prazo é impróprio; b) para a decisão sobre a pronúncia, diante da necessidade de ouvir todos os depoimentos gravados; c) na intimação pessoal do réu pelo oficial de justiça, para marcar o início do prazo recursal. Medida adotada: concentração de atos em audiência e oralidade, com as seguintes etapas: a) havendo concordância das partes, as alegações finais são apresentadas na forma oral, gravando-se no sistema de áudio e vídeo (utilizado para gravar os depoimentos), apenas se consignando na ata o pedido final da parte; b) a decisão sobre a pronúncia ocorre no próprio ato, quando não se trata de processo complexo; c) se não há recurso (mediante manifestação expressa das partes nesse sentido), consigna-se em ata a preclusão, bem como se abre a fase do art. 422 do CPP, com a apresentação do rol de testemunhas e pedido de diligências pelas partes; d) sendo possível, profere-se a decisão prevista no art. 423 do CPP, designando-se data para sessão de julgamento pelo júri, com intimação das partes e de todos os presentes. Sempre se analisa a complexidade do processo e a habilidade de todos os atores para praticarem os atos de forma oral, a fim de que, sem açodamento, ocorra a máxima qualidade da manifestação das partes e da decisão judicial, sempre preservando-se a ética, a legalidade, a boa-fé processual e a transparência. Resultado observado: em razão da possibilidade de concentração máxima de atos na audiência de instrução, todos os sujeitos processuais precisam se preparar melhor para a sua prática de forma imediata e oral. Com isso, há um aumento muito significativo na qualidade das perguntas das partes durante os depoimentos, bem como melhora substancial na acusação e na defesa do réu. Além disso, representa economia de tempo e otimização do processo, garantindo-se, ao mesmo tempo, a máxima qualidade dos atos processuais e a celeridade.

Diagnóstico 7: na sessão de julgamento do Tribunal do Júri, havia, em maior ou menor medida, deficiência de compreensão dos jurados sobre onde cada tese de acusação e defesa se encaixava nos quesitos. 
Medida adotada: preparação e prévia entrega da minuta de quesitos (a serem votados pelos jurados) ao Ministério Público e à defesa, logo no início da abertura do prazo de sustentação pelo primeiro, para que as partes possam defender as suas teses com essa minuta de quesitação em mãos, sem prejuízo de sua readequação posterior às teses suscitadas nos debates. Resultado observado: embora o Código de Processo Penal exija que os quesitos sejam apresentados às partes ao final da fase de sustentação em plenário (art. 484, caput), essa medida de antecipação de entrega de uma minuta da quesitação é relevante para que os jurados tomem uma decisão mais informada, haja vista que possibilita que Ministério Público e defesa exponham onde as suas teses se encaixam dentro dos quesitos e peçam aos jurados que votem "sim" ou "não" em cada quesito, se acolhidas as suas respectivas teses.

Diagnóstico 8: sessões plenárias muito longas por réplicas desnecessárias, que têm como consequência o cansaço e a desatenção dos jurados, em prejuízo à qualidade do seu julgamento. Medida adotada: embora o juiz-presidente, por óbvio, não possa impedir o uso da réplica pelo Ministério Público, pode sugerir às partes que, em vez da réplica (e consequente tréplica), ocorra um breve aparte durante as sustentações da acusação e da defesa, o que garante que apresentem as suas visões sobre a questão, informando adequadamente as suas teses aos jurados, sem o dilargamento desnecessário da sessão do júri. Resultado observado: otimização da sessão de julgamento, pela redução de réplicas desnecessárias, sempre por vontade expressa das próprias partes, com garantia da máxima qualidade dos debates entre acusação e defesa, bem como de maior esclarecimento e informação aos jurados.

Diagnóstico 9: ausência de aferição sobre como o jurado enxerga a sua atuação no Tribunal do Júri e acerca de como foi recebido e atendido. Medida adotada: aplicação de questionário de avaliação pelo jurado, no qual ele pode avaliar, sem se identificar, como foi o atendimento prestado pelo magistrado, pelos servidores e colaboradores, além de expor como foi a sua experiência no Tribunal do Júri e apontar pontos passíveis de melhorias. Resultado observado: melhor atendimento prestado ao jurado, para deixá-lo mais confortável, pois ele é quem faz o julgamento no Tribunal do Júri. Pela análise das respostas dos jurados, foi possível observar um aumento do grau de satisfação dos jurados ao longo do tempo.

Diagnóstico 10: ausência de gestão de dados, para saber qual é o impacto da efetividade processual na sociedade. Medida adotada: 
criação de gráfico, indicando, mensalmente, o quantitativo de homicídios e tentativas de homicídios, bem como de distribuição de inquéritos e de ações penais. Esse gráfico permite a gestão de dados e a avaliação da efetividade de todos os atores. Por exemplo, se a distribuição de inquéritos estiver aumentando e a de ações penais diminuindo, isso pode indicar que o Ministério Público está represando a propositura de ações, ou que a Polícia Judiciária não está sendo efetiva nos inquéritos, o que impede que o Ministério Público tenha elementos probatórios suficientes para propor a ação penal. De outro lado, se o quantitativo de crimes dolosos contra a vida estiver aumentando e o quantitativo de inquéritos distribuídos diminuindo, talvez haja um problema de falta de instauração de inquéritos policiais, o que precisa ser apurado. Resultado observado: o gráfico permite o acompanhamento da vara, assim como aferir a efetividade dela, do Ministério Público e da Polícia Judiciária; também possibilita o planejamento da unidade judicial, a curto, médio e longo prazo, pois pode indicar que haverá aumento, manutenção ou redução do quantitativo de processos.

O gráfico elaborado pela unidade judicial é o seguinte:

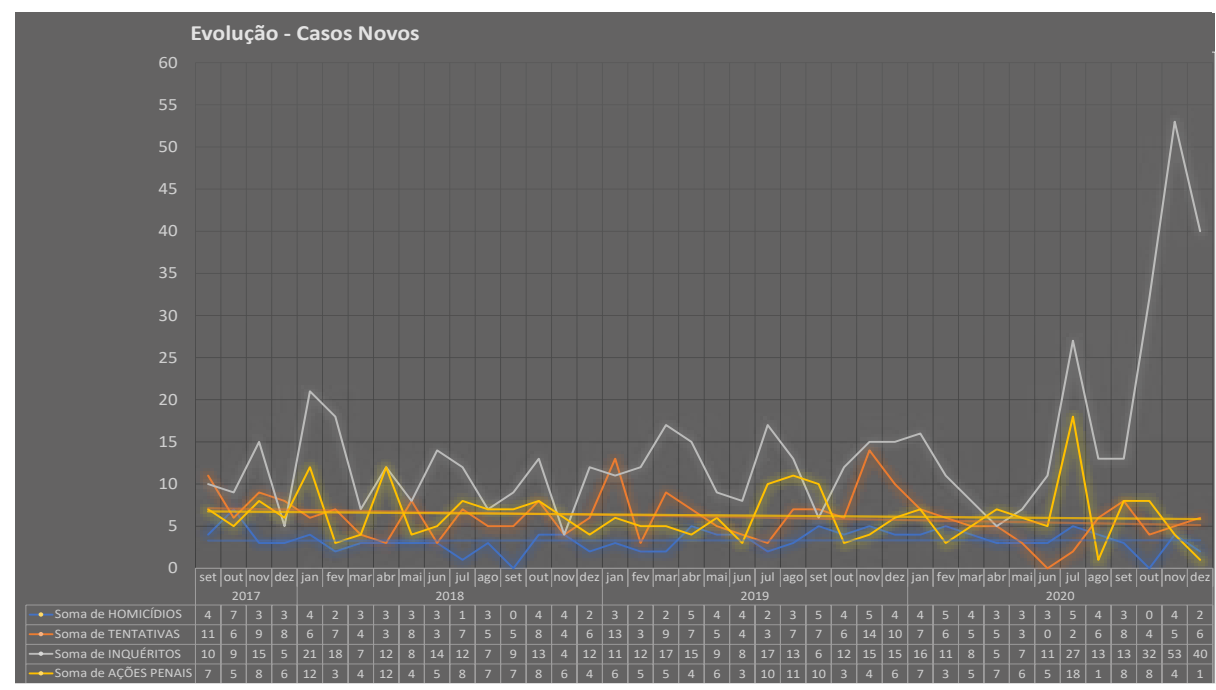


Neste tocante, é possível observar que o quantitativo de homicídios, tentativas de homicídios e ações penais permanece constante, mas o número de inquéritos possui picos nos meses de julho, outubro, novembro e dezembro de 2020. Ocorre que, em consulta com a unidade judicial, foi possível observar que isso se deveu à incorreção de dados do sistema, gerada pela digitalização dos inquéritos pelo Ministério Público. Em junho de 2020, houve a implementação do Processo Judicial Eletrônico - PJe na unidade judicial, mas os inquéritos policiais continuaram sendo formulados de forma física. Assim, com a entrega dos autos dos inquéritos ao Ministério Público, este promovia a digitalização e a inserção no sistema PJe, mas com outro número, de modo que, no sistema do TJDFT, o mesmo inquérito foi computado duas vezes (porque os meios virtual e físico tinham números diferentes). Retirando-se essa inconsistência, é possível observar que o quantitativo de homicídios consumados, homicídios tentados, ações penais e inquéritos policiais permanece com uma tendência de se manter constante.

Segundo consta no Banco de Boas Práticas do CNJ, essas seriam as principais práticas que levaram o Tribunal do Júri de Samambaia a atingir o primeiro lugar no ranking nacional de desempenho em 2020, relativo a 2019. No ano seguinte (2021 relativo ao ano-base 2020), a unidade judicial novamente atingiu o primeiro lugar no ranking nacional de desempenho.

Para se aferir, dentro do desempenho, a qualidade dos julgamentos, seguiu-se a métrica utilizada no Diagnóstico das Ações Penais de Competência do Tribunal do Júri (CNJ), de modo que se analisou, na unidade judicial em referência, se houve aumento ou diminuição do quantitativo de decisões extintivas de punibilidade (que englobam a prescrição penal, perda da pretensão punitiva estatal em razão da inércia estatal), comparativamente às decisões de mérito (condenatórias ou absolutórias). Além disso, fez-se uma análise comparativa entre decisões condenatórias e absolutórias, o que também pode indicar aumento ou diminuição do desempenho (no atributo qualidade), ainda que este dado não seja absoluto.

Embora se pretendesse realizar a pesquisa de 2017 a 2020, observou-se que, em 2020, houve um decréscimo do quantitativo de realização de sessões plenárias de júri, haja vista que as atividades presenciais, em razão da pandemia de Covid-19, foram suspensas pelo TJDFT no período de 19 de março até o final de agosto de 2020, tendo 
a unidade judicial em referência retomado as sessões de julgamento somente em 10 de setembro do mesmo ano. Desse modo, como não houve sessões do júri em metade do referido ano, para se realizar uma análise da produtividade em condições normais, foi pesquisado o período de 2017 a 2019, colocando-se os dados no seguinte gráfico:

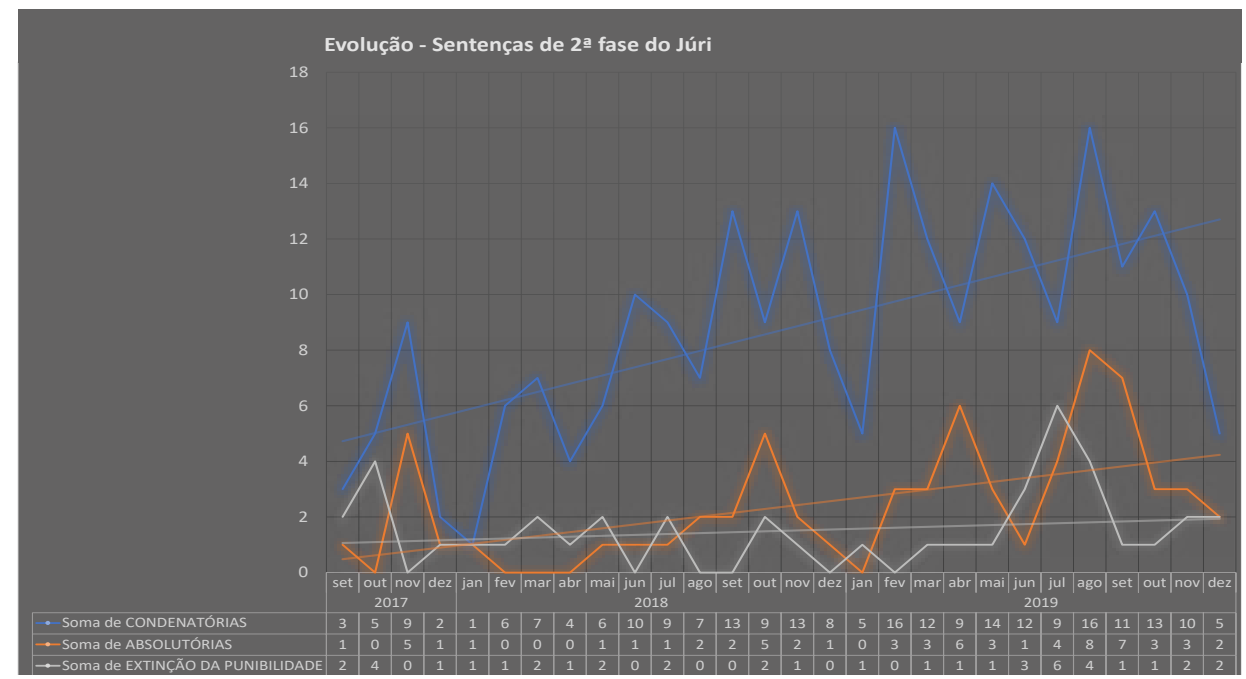

Observa-se que, considerando as linhas de tendência, não há acréscimo nas sentenças extintivas da punibilidade, bem como que houve aumento de julgamentos de mérito, sendo que o acréscimo de sentenças condenatórias é bem superior ao crescimento das sentenças absolutórias. Como o aumento da qualidade da prova induz ao aumento de condenações - haja vista que, no processo penal, havendo dúvida, o réu deve ser absolvido - esse gráfico pode indicar que houve aumento na qualidade do julgamento, embora haja outros indicadores para aferir tal atributo do desempenho.

\section{CONCLUSÃO}

Alguns indicadores de desempenho do Judiciário brasileiro têm melhorado desde 2017, como o aumento do índice de atendimento à demanda e a redução do acervo processual. De outro lado, o tempo do processo continua elevado, o que prejudica a efetividade judicial. No âmbito dos tribunais do júri, em especial, ainda há um grande déficit de efetividade, considerando que cerca de um terço dos processos possuem 
decisão extintiva da punibilidade, que mais da metade dos processos duram quatro anos ou mais e que mais de um quarto deles chegam a tramitar por mais de oito anos. Nesse sentido, as medidas de gestão judicial podem ser grandes aliadas do Poder Judiciário no aumento do seu desempenho, como apontado pelo Conselho Nacional de Justiça.

Sob uma perspectiva de direito comparado, observa-se que, em países como Portugal e Reino Unido, a gestão de processos é um dever imposto ao juiz pela legislação, com uma série de instrumentos jurídicos para acelerar o processo e poderes processuais para coibir atos protelatórios. No Brasil, as legislações processuais não fazem referência à gestão de processos, bem como se observa que ela representa um potencial ainda pouco explorado.

Embora muitas técnicas e estratégias de gestão de outros países, do setor privado e da administração pública brasileira em geral possam ser aplicados às unidades judiciais no Brasil, é imprescindível conhecer a sua realidade e as suas especificidades, a fim de que se possa propor medidas de gestão e criar ferramentas capazes de efetivamente melhorar a qualidade do gerenciamento dos seus processos.

Pesquisas empíricas possuem um grande potencial para analisar as dinâmicas internas ao sistema de justiça brasileiro, bem como identificar os problemas, os entraves e os gargalos institucionais e práticos que geram inefetividade processual e afetam o Poder Judiciário na otimização dos processos e dos julgamentos, a fim de que sejam propostas alternativas viáveis aos seus modos de funcionamento.

No cenário nacional, algumas unidades judiciais têm se destacado pelo elevado desempenho, o que precisa ser objeto de análise e mapeamento para replicação. O Tribunal do Júri de Samambaia, objeto do estudo de caso desenvolvido nesta pesquisa, representa um bom exemplo de que medidas de gestão processual, muitas vezes de simples e rápida implementação, possuem elevado impacto no desempenho da unidade e no Judiciário. Além de ter conquistado o primeiro lugar no ranking nacional de desempenho nos anos-base 2019 e 2020, a unidade teve uma taxa de congestionamento, no último ano, que é quase um terço da média nacional.

Como foi anotado pelo Tribunal do Júri de Samambaia no Banco de Boas Práticas do CNJ, bem como em reportagens sobre a sua atuação, o seu desempenho foi atribuído em grande medida à gestão processual. Nesta vara judicial, foi desenvolvida uma metodologia que 
contempla a realização de diagnósticos, a criação de medidas viáveis e o acompanhamento de resultados, que podem ser facilmente exportados e adaptados para outras unidades judiciais, sobretudo de natureza criminal.

Pelos dados analisados no Tribunal do Júri de Samambaia, é possível constatar que essas medidas de gestão processual geraram aumento da produtividade, com redução da taxa de congestionamento, aumento dos julgamentos e diminuição do acervo processual. Além disso, indicam que houve aumento da qualidade dos julgamentos, diante da estabilização do quantitativo de sentenças extintivas da punibilidade, bem como aumento das sentenças condenatórias proporcionalmente às sentenças absolutórias, possivelmente pelo aumento da qualidade da produção da prova no processo judicial.

Portanto, a gestão processual produz grandes impactos no desempenho judicial, com aumento da celeridade do processo e da qualidade dos julgamentos. Nesse sentido, é importante que as unidades judiciais criem e implementem um modelo estratégico de gerenciamento de processos, que respeite as garantias das partes, esteja alicerçado na confiança e na cooperação, a fim de que melhorem o seu desempenho e contribuam para um Judiciário mais efetivo. 


\section{REFERÊNCIAS}

ALMEIDA, Diogo Assumpção Rezende de. O case management inglês: um sistema maduro? Revista Eletrônica de Direito Processual, Rio de Janeiro, v. 7, n. 7, p. 287-335, 2011.

ARAÚJO, Luis César G. de; GARCIA, Adriana Amadeu; MARTINES, Simone. Gestão de processos: melhores resultados e excelência organizacional. 2. ed. São Paulo: Atlas, 2019.

AKUTSU, Luiz; GUIMARÃES, Tomas de A. Dimensões da governança judicial e sua aplicação ao sistema judicial brasileiro. Revista Direito GV, São Paulo, v. 8, n. 1, p. 183-202, 2012.

CONSELHO NACIONAL DE JUSTIÇA (Brasil). Diagnósticos das custas processuais praticadas nos tribunais. Brasília, DF: CNJ, 2019.

CONSELHO NACIONAL DE JUSTIÇA (Brasil). Justiça em

Números 2018: ano-base 2017. Brasília, DF: CNJ, 2018.

Disponível em: http://www.cnj.jus.br/files/conteudo/ arquivo/2018/08/44b7368ec6f888b383f6c3de40c32167.pdf. Acesso em: 31 maio 2020.

CONSELHO NACIONAL DE JUSTICCA (Brasil). Justiça em números 2020: ano-base 2019. Brasília, DF: CNJ, 2020a. Disponível em: https:// www.cnj.jus.br/wp-content/uploads/2020/08/WEB-V3-Justi\%C3\%A7aem-N\%C3\%BAmeros-2020-atualizado-em-25-08-2020.pdf. Acesso em: 31 maio 2020.

CONSELHO NACIONAL DE JUSTIÇA (Brasil). Módulo de produtividade mensal: ano 2020, Tribunal do Júri, Competência Exclusiva, 2020b. Disponível em: https://paineis.cnj.jus.br/ QvAJAXZfc/opendoc.htm?document=qvw_l\%2FPainelCNJ.

qvw\&host=QVS\%4Oneodimio03\&anonymous=true\&sheet=shPDPrincipal. Acesso em: 10 fev. 2021.

CONSELHO NACIONAL DE JUSTICCA (Brasil). Plenário aprova oito boas práticas em gestão processual. Agência CNJ de Notícias, Brasília, 2020c. Disponível em: https://www.cnj.jus.br/plenario-aprova-oito-boaspraticas-em-gestao-processual/. Acesso em: 9 fev. 2021. 
CONSELHO NACIONAL DE JUSTICCA (Brasil). Tribunais do Júri do DF ficam em 10 e $2 \circ$ lugar em ranking nacional do CNJ. CNJ, Notícias do Judiciário, Brasília, 2020d. Disponível em: https://www.cnj.jus.br/ tribunais-do-juri-do-df-ficam-em-1o-e-2o-lugar-em-ranking-nacionaldo-cnj/. Acesso em: 9 fev. 2021.

DISTRITO FEDERAL (Brasil). Tribunal de Justiça do Distrito Federal e dos Territórios. Boletim de produtividade mensal dos juízos do Distrito Federal referente ao mês agosto 2017. Brasília, DF: Tribunal de Justiça do Distrito Federal e dos Territórios, 2017. Disponível em: https://www. tjdft.jus.br/estatisticas/produtividade/produtividade-dos-juizos/ano2017. Acesso em: 31 maio 2021.

DISTRITO FEDERAL (Brasil). Tribunal de Justiça do Distrito Federal e dos Territórios. Boletim de produtividade mensal dos juízos do Distrito Federal referente ao mês dezembro 2020. Brasília, DF: Tribunal de Justiça do Distrito Federal e dos Territórios, 2020. Disponível em: https://www.tjdft.jus.br/estatisticas/produtividade/produtividade-dosjuizos/copy_of_ano-2019. Acesso em: 31 maio 2021.

DISTRITO FEDERAL (Brasil). Tribunal de Justiça do Distrito Federal e dos Territórios Primeira Vice-Presidência. Coordenadoria de Apoio aos Magistrados. Processo SEI 0021803/2020. Despacho, 19 jan. 2021a.

DISTRITO FEDERAL (Brasil). Tribunal de Justiça do Distrito Federal e dos Territórios. Tribunais do Júri de Samambaia e de Brasília conquistam $1^{\circ}$ e $2^{\circ}$ lugar no ranking de desempenho nacional do $\mathrm{CNJ}$. Brasília, DF: Tribunal de Justiça do Distrito Federal e dos Territórios, 2021b. Disponível em: https://www.tjdft.jus.br/institucional/imprensa/ noticias/2021/fevereiro/tribunais-do-juri-de-samambaia-e-de-brasiliaconquistam-1o-e-2o-lugar-no-ranking-nacional-de-desempenho-docnj\#: : :text=Os\%2Otribunais\%20do\%20J\%C3\%BAri\%2Ode,com\%20 compet\%C3\%AAncia\%20exclusiva\%20do\%20pa\%C3\%ADs. Acesso em: 31 maio 2021.

EISENHARDT, Kathleen M. Building theories form case study research. Academy of Management Review, Nova lorque, v. 14, n. 4, p. 532-550, Oct. 1989.

ELLRAM, Lisa M. The use of the case study method in logistics research. Journal of Business Logistics, v. 17, n. 2, p. 93-138, 1996.

LUNARDI, Fabrício Castagna. Gestão processual estratégica no Tribunal do Júri. Portal CNJ de Boas Práticas do Poder Judiciário, Brasília, 
[2020a]. Disponível em: https://boaspraticas.cnj.jus.br/pratica/261. Acesso em: 9 fev. 2021.

LUNARDI, Fabrício Castagna. Gestão processual no Tribunal do Júri. Brasília: Conselho Nacional de Justiça, 2020b. Disponível em: https:// www.cnj.jus.br/wp-content/uploads/2020/07/Gesta\%CC\%83o_ processual_no_Tribunal_do_Ju\%CC\%81ri_02_07-1.pdf. Acesso em: 31 maio 2021.

LUNARDI, Fabrício Castagna. Processo, gestão judicial e efetividade: por um novo campo de estudo. 2019. Disponível em: https://www.tjdft. jus.br/institucional/imprensa/campanhas-e-produtos/artigos-discursose-entrevistas/artigos/2019/processo-gestao-judicial-e-efetividade-porum-novo-campo-de-estudo-juiz-fabricio-castagna-lunardi. Acesso em: 31 maio 2021.

MONTENEGRO, Manuel Carlos. Juízes do Tribunal do Júri correm contra o tempo e impunidade de assassinos. Agência CNJ de Notícias, Brasília, 2021. Disponível em: https://www.cnj.jus.br/juizes-do-tribunal-do-juricorrem-contra-o-tempo-e-impunidade-de-assassinos/. Acesso em: 31 maio 2021.

PORTUGAL. Lei n. 41, de 26 de junho de 2013. Aprova o Código de processo civil. Lisboa, 2013. Disponível em: https://dre.pt/web/guest/ legislacao-consolidada/-/Ic/124532393/202105311618/73790239/ exportPdf/normal/1/cacheLevelPage?_LegislacaoConsolidada_WAR_ drefrontofficeportlet_rp=diploma. Acesso em: 31 maio 2021.

PORTUGAL. Decreto-Lei n. 1.978, de 17 de fevereiro de 1987. Aprova o Código do processo penal. Revoga o Decreto-lei n. 16.489, de 15 de fevereiro de 1929. Lisboa, 1987. Disponível em: https://dre.pt/web/guest/ legislacao-consolidada/-/Ic/117352444/201902151332/exportPdf/normal/1/ cacheLevelPage?_LegislacaoConsolidada_WAR_drefrontofficeportlet_ rp=diploma. Acesso em: 31 maio 2021.

REINO UNIDO. Civil Procedure Rules 1998. Londres: Ministério de Justiça, 1998. Disponível em: https://www.justice.gov.uk/courts/ procedure-rules/civil/rules. Acesso em: 31 maio 2021.

REINO UNIDO. Criminal Procedure Rules 2020. Londres: Ministério de Justiça, 2020. Disponível em: https://www.legislation.gov.uk/ uksi/2020/759/contents/made. Acesso em: 31 maio 2021. 
SILVA, Paula Costa e. Legalidade das formas de processo e gestão processual ou as duas faces de Janus. Revista de Informação

Legislativa, Brasília, ano 48, n. 190, p. 137-149, abr./jun. 2011.

SORDI, José Osvaldo de. Gestão por processos: uma abordagem da moderna administração. 5. ed. São Paulo: Saraiva, 2018.

YIN, Robert K. Case study research: design and methods. 4th ed. California: Sage Publications, 2009. 